\title{
Commentary: No blame! Let us look at our work without pointing fingers
}

\author{
Yves d'Udekem, MD, PhD, FRACS, ${ }^{a, b, c}$ and \\ Federica Caldaroni, MD
}

Nathan and colleagues ${ }^{1}$ present the premise of a large collaborative work that will look at residual lesions after surgery. One can be critical of this work because of the inference that if postsurgery results are not good, well, it is likely that outcomes will not be good, either. So why bother?

However, it should be first realized that we have been extremely poor at predicting outcomes after pediatric cardiac surgery. In a very recent work, analyzing 8406 procedures collected in the Paediatric Cardiac Critical Care Consortium, for example, Pasquali and colleagues ${ }^{2}$ demonstrated that all the best conventionally known risk factors, including STAT score, could only explain $30 \%$ of the individual variation in observed mortality. The differences among our surgeries are rarely analyzed, but it is likely that it is in these differences that lies the discrepancy in the observed results. Under the same generic intervention names, in fact, we are providing very different operations, with different indications, different thresholds for immediate reintervention and, unsurprisingly, our results vary. ${ }^{3}$ The topic is likely taboo because we are always afraid to categorize ourselves on a scale of good to bad surgeons. This is a mistake. I do not know any surgeon who conscientiously wants to do a "bad job." We all put the best of ourselves in our surgeries. And even the best among us suffer complications. It took me the best of the last 2 decades to understand that my job was not to avoid any complications but in being good at treating them. We have reduced the

From the ${ }^{a}$ Department of Cardiac Surgery, Royal Children's Hospital, ${ }^{\mathrm{b}}$ Heart Research, Murdoch Children's Research Institute, and ' Department of Paediatrics, The University of Melbourne, Melbourne, Australia.

Disclosures: Dr d'Udekem is a consultant for MSD and Actelion. He also is a NHMRC Clinician Practitioner Fellow [1082186]. Dr Caldaroni has nothing to disclose with regard to commercial support.

Received for publication Nov 6, 2019; accepted for publication Nov 7, 2019; available ahead of print Nov 29, 2019.

Address for reprints: Yves d'Udekem, MD, PhD, FRACS, Department of Cardiac Surgery, The Royal Children's Hospital Melbourne, 50 Flemington Rd, Parkville, 3052 Victoria, Australia (E-mail: yves.dudekem@rch.org.au).

J Thorac Cardiovasc Surg 2020;160:224-5

0022-5223/\$36.00

Copyright (c) 2019 by The American Association for Thoracic Surgery

https://doi.org/10.1016/j.jtcvs.2019.11.045

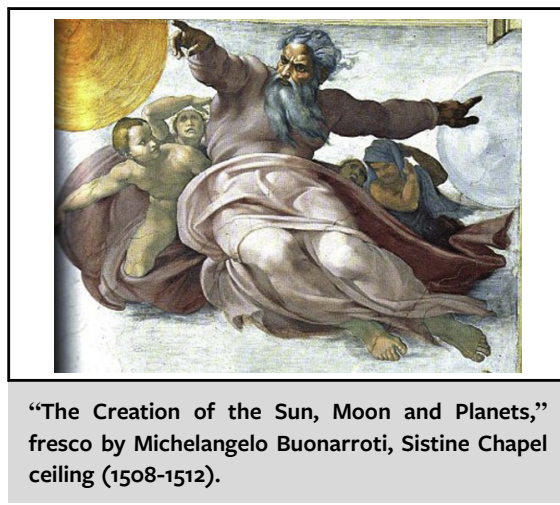

CENTRAL MESSAGE

Improvement of care in pediatric

cardiac surgery goes through a

careful and honest analysis of

outcomes and performances,

with no space for blame.

mortality of our overall patient population to an unbelievable $0.5 \%$ to $1 \%,{ }^{4}$ but I still have days when I believe that the majority of my patients suffer from some sort of complication.

The result of our surgeries is the combination of the indications, perioperative management, differences in our beliefs of best procedures, our education, and the acceptance or nonacceptance of our results. And it is time that we look at those outcomes without blame. It is therefore a very welcome initiative to rename the "Technical Performance Score" a "Residual Lesions Score" because it highlights that the ultimate result of the surgery is the result of the interaction of a specific patient with an entire team who has at its core a surgeon who gave their absolute best. This initiative is a first major step toward a progress in the field. The fact that it is supported by so many prestigious US centers speaks of its relevance. It presents a preliminary outlook of a much more important work that will soon be done, but it is important to share this work at this preliminary stage because it gives us an opportunity to react to their classification. I invite you to look how considerate were the decisions they took in classifying these residual lesions and share your reactions if you were in disagreement.

If we want to progress in the care of our patients, we have to look more closely at the immediate results of our surgery. Without blame. 


\section{References}

1. Nathan M, Trachtenberg FL, Van Rompay MI, Gaynor W, Kanter K, Ohye R, et al. The pediatric heart network residual lesion score study: design and objectives. $J$ Thorac Cardiovasc Surg. 2020;160:218-23.e1.

2. Pasquali SK, Gaies M, Banerjee M, Zhang W, Donohue J, Russell M, et al. The quest for precision medicine: unmeasured patient factors and mortality after congenital heart surgery. Ann Thorac Surg. 2019;108:1889-94.
3. d'Udekem Y, Galati JC, Konstantinov IE, Cheung MH, Brizard CP. Intersurgeon variability in long-term outcomes after transatrial repair of tetralogy of Fallot: 25 years' experience with 675 patients. J Thorac Cardiovasc Surg. 2014;147:880-6.

4. Dagan M, Butt W, Millar J, d'Udekem Y, Thompson J, Namachivayam SP. Changing risk of in-hospital cardiac arrest in children following cardiac surgery in Victoria, Australia, 2007-2016. Heart Lung Circ. November 23, 2018 [Epub ehead of print].
See Article page 218.

\section{Commentary: Technical excellence is necessary but not sufficient}

David P. Bichell, MD

A wise elder surgeon observed that the outcome of an arterial switch procedure depends mostly on operative technical performance, whereas the outcome of the Norwood procedure depends in near equal part on the postoperative art of anticipation and the mitigation of instability before it happens. If a good surgical outcome can be divided into contributing components, then surely not all operations are equal. For some lesions, outcomes depend most heavily on a postoperative flight plan followed by a dedicated team that can recognize an imbalance and correct it before compounding reactions propagate risk.

In this issue of the Journal, Nathan and colleagues ${ }^{1}$ describe an ambitious prospective study of the Residual Lesion Score (RLS), a refinement of the technical performance score, ${ }^{2,3}$ hypothesizing that a postoperative echocardiogram may be a measure not only of operative adequacy, but may serve as a composite assay that speaks to preoperative diagnostic acumen, intraoperative decision making, surgical technical prowess, and postoperative complications. The study purports to discover which structural

\footnotetext{
From the Department of Cardiac Surgery, Monroe Carell, Jr, Children's Hospital, Vanderbilt University Medical Center, Nashville, Tenn.

Disclosures: Author has nothing to disclose with regard to commercial support.

Received for publication Dec 2, 2019; accepted for publication Dec 2, 2019; available ahead of print Dec 20, 2019.

Address for reprints: David P. Bichell, MD, Department of Cardiac Surgery, Monroe Carell, Jr, Children's Hospital, Vanderbilt University Medical Center, 5247 Doctors' Office Tower, 2200 Children's Way, Nashville, TN 37232-9292 (E-mail: david.bichell@vumc.org)

J Thorac Cardiovasc Surg 2020;160:225-6 $0022-5223 / \$ 36.00$

Copyright (c) 2020 Published by Elsevier Inc. on behalf of The American Association for Thoracic Surgery

https://doi.org/10.1016/j.jtcvs.2019.12.008
}

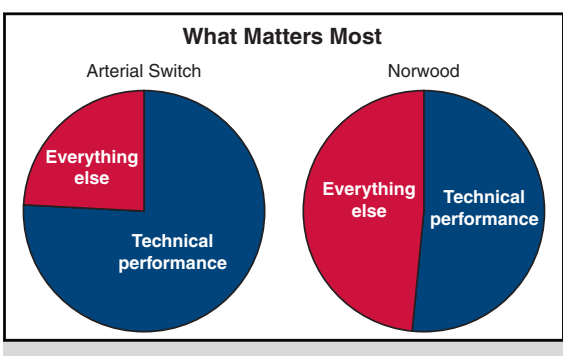

Surgical versus perioperative contributions to outcome are procedure-dependent.

\section{CENTRAL MESSAGE \\ A Residual Lesion Score that uses a discharge echocardio- gram of the repaired heart to predict ultimate outcome may be strengthened by the addition of measures beyond just heart architecture.}

subcomponents of a repair have the strongest association with outcome measures based on the RLS.

The RLS is an undoubtedly a valuable outcome predictor, and the proposed study will reveal refinements that widen its scope. Future iterations will likely find cause to include additional elements beyond a snapshot of the architecture of the repaired heart.

The current RLS is a structural assay, not functional. Diastolic or systolic ventricular dysfunction from incomplete myocardial protection or prolonged cross-clamp time, phrenic nerve or vocal cord paralysis, bronchomalacia, and coronary compression are among the factors that are not scored by the current RLS but deeply affect postoperative and long-term outcomes. It is encouraging to anticipate the inclusion of some measures of ventricular and respiratory function in the RLS to broaden its predictive value. 